\title{
Analysis of the Competitiveness of Growth Enterprise Market Listed Companies IPO in 2015 in China
}

\author{
Zhixin Liang \\ School of information, Beijing Wuzi University, Beijing, China \\ Email:liangzhixin@sina.com
}

How to cite this paper: Liang, Z.X. (2017) Analysis of the Competitiveness of Growth Enterprise Market Listed Companies IPO in 2015 in China. Open Journal of Modelling and Simulation, 5, 232-240.

https://doi.org/10.4236/ojmsi.2017.54017

Received: August 21, 2017

Accepted: October 13, 2017

Published: October 16, 2017

Copyright $\odot 2017$ by author and Scientific Research Publishing Inc. This work is licensed under the Creative Commons Attribution International License (CC BY 4.0).

http://creativecommons.org/licenses/by/4.0/

\begin{abstract}
Based on the 2016 annual data, the article studies the competitiveness of 87 listed companies, who initially went public on China's GEM in 2015. Taking 12 financial indicators (current ratio, quick ratio, equity ratio, receivables turnover, current asset turnover, total asset turnover, operating margin, net profit margin, return on total assets, total asset growth rate, net profit growth rate, net asset growth rate) as research variables, using factor analysis, the article analyzes the solvency, operation performance, profitability, growth capability and overall competitiveness of these 87 listed companies.
\end{abstract}

\section{Keywords}

GEM, Listed Companies, Competitiveness, Factor Analysis

\section{Introduction}

Since the reform and opening, Chinese economy has obtained considerable progress. Meanwhile, China's capital market has also gradually improved. On November 12, 2013, “The CPC Central Committee's decision regarding several major issues of comprehensive reform" clearly pointed out that "establishing multi-level capital market system and promoting the reform of registration-based stock issuance". Since then, IPOs have significantly accelerated. From December 19, 1990 the first issuance of private stock, to the end of 2013, the total number of stocks in China A-share market has reached 2463, and by the end of 2016, this number reached 3178. Among them, the GEM market's performance has been compelling during the short few years since the official launching in October 2009.

There are many relevant literatures on the competitiveness of listed compa- 
nies. Some of them take policy makers, managers and managers as the research perspective [1] [2]. [3] [4] [5] study the company from management, business model and market strategy. The competitiveness of listed companies in an industry is analyzed in some papers [6] [7] and the empirical analysis of regional listed companies' competitiveness is conducted in some papers [8] [9]. There are few quantitative researches on the competitiveness of GEM listed companies. The competitiveness of 355 listed companies in China's GEM was studied by Liu Hongjie, Wang Shuwei (2015) [10]. Through grey correlation analysis on MATLAB, they concluded that companies in cultural industry have the strongest competitiveness, and those in manufacturing have the weakest one.

As an important part of the multi-level capital market, the GEM has been favored by domestic venture capitals since launching, mainly for the high growth capability. In addition, private capital also loves to invest in high-tech enterprises, because these growth-oriented enterprises are the promoting drivers of China's industrial structure upgrades.

GEM has opened up broad financing platforms for the growing innovative enterprises, high-tech enterprises and outstanding SMEs, as well as effectively guided the capital from venture capital and industrial capital to flow to high-tech industries and new economic industries.

The forward-looking, highly risky, and unique structure often leads to radical fluctuations. Meanwhile, as the Chinese stock market is not mature enough, some risk-loving investors did not truly explore the company's long-term investment value and potential. Therefore, nowadays, in the rapid developing capital market in China, the topic of how to possess a rather objective and accurate judgement on the market competitiveness of Chinese listed companies through various financial indicators is worth discussing.

Based on the 2016 annual data, this article studies the competitiveness of 87 listed companies, who initially went public on China's GEM in 2015. Taking 12 financial indicators (current ratio, quick ratio, equity ratio, receivables turnover, current asset turnover, total asset turnover, operating margin, net profit margin, return on total assets, total asset growth rate, net profit growth rate, net asset growth rate) as research variables, using factor analysis, the article analyzes the solvency, operation performance, profitability, growth capability and overall competitiveness of these 87 listed companies.

\section{Introduction of Mathematical Models and Analysis Process of Factor Analysis}

\subsection{Data Collection of Listed Companies}

The 87 on China's GEM listed companies fall into 24 industry categories, of which 61 listed companies belong to manufacturing (including special equipment manufacturing, instrumentation manufacturing, pharmaceutical manufacturing, general equipment manufacturing, railway, shipping, aerospace and other transportation equipment manufacturing, computer, communications and 
other electronic equipment manufacturing, electrical machinery and equipment manufacturing), 10 listed companies belong to software and information technology services, and the remaining 16 listed companies belong to other sectors. This article chooses four categories of 12 financial indicators to analyze the competitiveness of the above 87 listed companies. The first category reflects the solvency: current ratio, quick ratio, equity ratio. The second category reflects the operating performance: receivables turnover, current asset turnover, total asset turnover. The third category reflects the profitability: operating margin, net profit margin and return on total assets. The fourth category reflects growth capability: total asset growth rate, net profit growth rate and net asset growth rate. These 12 indicators are recorded as $X_{1}, X_{2}, \cdots, X_{12}$. According to the 2016 annual data gathered from Shenzhen Stock Exchange website, the 12 financial indicators data can be obtained through calculation.

\subsection{Mathematical Models and Analysis Process}

Factor analysis is a multivariate statistical method that transforms multiple measured variables into a few unrelated composite indicators. These composite indicators are not related to each other, that is, the information represented by each indicator does not overlap and reflects the nature of things. Thus, we are able to name the composite indicators based on professional knowledge and the unique meanings reflected by indicators. These composite indicators are called factors.

Let the original variables and factors be $X_{1}, X_{2}, \cdots, X_{m}$ and $F_{1}, F_{2}, \cdots, F_{p}$ respectively. The mathematical model of factor analysis is

$$
\left\{\begin{array}{c}
X_{1}=b_{11} F_{1}+b_{12} F_{2}+\cdots+b_{1 p} F_{p}+\varepsilon_{1} \\
X_{2}=b_{21} F_{1}+b_{22} F_{2}+\cdots+b_{2 p} F_{p}+\varepsilon_{2} \\
\vdots \\
X_{m}=b_{m 1} F_{1}+b_{m 2} F_{2}+\cdots+b_{m p} F_{p}+\varepsilon_{m}
\end{array}\right.
$$

Expressed as a matrix form $X=B F+E$, where $B$ is the factor load matrix, $F_{1}, F_{2}, \cdots, F_{p}$ which is not related to each other, $E$ is a special factor, contains random errors. The purpose of factor analysis is to get the common factor load factor and residual $E$, if the residual $E$ effect is negligible, then $X=B F$. That is a special form of factor analysis when $F_{1}, F_{2}, \cdots, F_{p}$ are not related to each other, the mathematical model can be expressed as:

$$
\left\{\begin{array}{c}
F_{1}=a_{11} X_{1}+a_{12} X_{2}+\cdots+a_{1 m} X_{m} \\
F_{2}=a_{21} X_{1}+a_{22} X_{2}+\cdots+a_{2 m} X_{m} \\
\vdots \\
F_{p}=a_{m 1} X_{1}+a_{m 2} X_{2}+\cdots+a_{p m} X_{m}
\end{array}\right.
$$

Expressed as a matrix form $F=A X, F_{1}, F_{2}, \cdots, F_{p}$ are also known as the principal component. The principal component analysis is to find the coefficient matrix $A$, so that the proportion of $F_{1}, F_{2}, \cdots, F_{p}$ in the total variance decreases in turn. 
The specific process of factor analysis goes as follows:

1) Conduct applicability test. In this paper, KMO and Bartlett spherical tests are performed, where the Kaisex-Meyer-Olkin measure verifies whether the partial correlation between the variables is small and whether the Bartlett's test of sphericity is a unit matrix.

2) Select the analysis matrix. This paper specifies the basis for analyzing the correlation coefficient matrix of the variables as the extraction factor.

3) Conduct factor extraction. In this paper, we will select the principal component analysis to obtain the initial factor analysis results, which specify the extraction of eigenvalues greater than 1 factor.

4) Conduct factor rotation, so that the meanings of factors are clear, and the factors are named. In this paper, we choose the maximum rotation of variance, which is an orthogonal rotation method that minimizes the number of variables with the highest load on each factor, and simplifies the interpretation of the factor.

5) Calculate factor scores for further analysis.

\section{Empirical Analysis of the Competitiveness of GEM Listed Companies IPO in 2015 in Chin}

In this paper, software "Statistical Product and Service Solutions (SPSS)" is used to analyze the selected 12 financial indicators data.

\subsection{Applicability Test of Data}

The correlation coefficient matrix of the original data is verified by KMO and Bartlett sphericity, and the KMO test value is obtained $0.708>0.6$. The spherical test is significant, $P($ sig. $=0.000)<0.05$. The data selected in this paper is suitable for factor analysis.

\subsection{Factor Extraction and Naming}

The principal component analysis method is used to obtain the eigenvalue and the cumulative variance contribution rate of the correlation coefficient matrix. The maximum variance method of the chair load matrix is selected to obtain the Table 1 and Table 2.

There are totally 4 factors with eigenvalues of more than 1 , their cumulative contribution rate was $89 \%>85 \%$. This result meets the requirement of cumulative contribution rate. Therefore, these four factors are selected:

The principal component F1 is mainly used to explain current ratio, quick ratio, equity ratio, which mainly reflect the solvency of listed companies. Thus, F1 can be called as solvency capacity factor; F2 is mainly used to explain operating margin, net profit margin, return on total assets, which focus on the level of profitability of listed companies. Thus, F2 can be called profitability factor; F3 is mainly used to explain receivables turnover, current asset turnover, total asset turnover, which reflect the level of operation of listed companies. Thus, F3 can be 
Table 1. Total variance explained.

\begin{tabular}{ccccccc}
\hline & \multicolumn{3}{c}{ Initial eigenvalues } & \multicolumn{3}{c}{$\begin{array}{c}\text { Extraction sums of squared } \\
\text { loadings after rotation }\end{array}$} \\
\cline { 2 - 7 } Component & Total & $\begin{array}{c}\text { \% of } \\
\text { Variance }\end{array}$ & cumulative \% & Total & $\begin{array}{c}\text { \% of } \\
\text { Variance }\end{array}$ & cumulative\% \\
\cline { 2 - 7 } & 4.499 & 37.494 & 37.494 & 3.017 & 25.142 & 25.142 \\
2 & 2.628 & 21.897 & 59.392 & 2.881 & 24.006 & 49.149 \\
3 & 2.357 & 19.640 & 79.032 & 2.455 & 20.462 & 69.610 \\
4 & 1.233 & 10.274 & 89.306 & 2.363 & 19.696 & 89.306 \\
\hline
\end{tabular}

Table 2. Component matrix after rotation.

\begin{tabular}{ccccc}
\hline & \multicolumn{4}{c}{ Component } \\
\cline { 2 - 5 } & 1 & 2 & 3 & 4 \\
\hline current ratio & 0.949 & 0.249 & -0.110 & -0.074 \\
quick ratio & 0.948 & 0.233 & -0.124 & -0.055 \\
equity ratio & 0.918 & 0.235 & -0.060 & 0.171 \\
receivables turnover & 0.037 & 0.191 & 0.763 & -0.008 \\
current asset turnover & -0.196 & -0.029 & 0.935 & 0.080 \\
total asset turnover & -0.136 & -0.107 & 0.878 & -0.091 \\
operating margin & 0.348 & 0.903 & -0.082 & 0.080 \\
net profit margin & 0.360 & 0.902 & -0.147 & 0.047 \\
return on total assets & 0.217 & 0.839 & 0.377 & -0.157 \\
total asset growth rate & -0.033 & -0.042 & -0.057 & 0.958 \\
net profit growth rate & -0.079 & 0.569 & 0.149 & 0.652 \\
net asset growth rate & 0.105 & -0.041 & -0.037 & 0.967 \\
\hline
\end{tabular}

called operating performance capacity factor; F4 is mainly used to explain the total asset growth rate, net profit growth rate, net asset growth rate, which focus on the ability to reflect the development of listed companies. Thus, F4 can be called the development capability factor.

\subsection{Factor Scoring and Ranking}

The four factor scores of 87 listed companies were calculated by least squares regression method:

$$
\left\{\begin{aligned}
F_{1}= & 0.376 X_{1}+0.378 X_{2}+0.376 X_{3}+0.065 X_{4}+0.034 X_{5}+0.071 X_{6} \\
& -0.071 X_{7}-0.074 X_{8}-0.065 X_{9}+0.01 X_{10}-0.148 X_{11}+0.078 X_{12} \\
F_{2}= & -0.106 X_{1}-0.113 X_{2}-0.123 X_{3}+0.015 X_{4}-0.053 X_{5}-0.092 X_{6} \\
& +0.355 X_{7}+0.359 X_{8}+0.328 X_{9}-0.061 X_{10}+0.247 X_{11}-0.097 X_{12} \\
F_{3}= & 0.047 X_{1}+0.043 X_{2}+0.072 X_{3}+0.325 X_{4}+0.393 X_{5}+0.379 X_{6} \\
& -0.072 X_{7}-0.1 X_{8}+0.115 X_{9}-0.005 X_{10}+0.018 X_{11}+0.021 X_{12} \\
F_{4}= & -0.027 X_{1}-0.018 X_{2}+0.08 X_{3}+0.003 X_{4}+0.052 X_{5}-0.017 X_{6} \\
& -0.01 X_{7}-0.025 X_{8}-0.101 X_{9}+0.412 X_{10}+0.25 X_{11}+0.42 X_{12}
\end{aligned}\right.
$$


The variance contribution rate of each common factor was calculated as weighted average of weight, and the comprehensive factor score:

$$
\begin{aligned}
F & =\left(25.142 F_{1}+24.006 F_{2}+20.462 F_{3}+19.696 F_{4}\right) / 89.306 \\
& =0.2815 F_{1}+0.2688 F_{2}+0.2291 F_{3}+0.2205 F_{4}
\end{aligned}
$$

lists the top 10 and the last 10 ranking companies based the comprehensive factor scores.

In Table 3, the serial numbers of companies location are: (1) Guangdong; (2) Zhejiang; (3) Hubei; (4) Beijing; (5) Hebei; (6) Jiangsu; (7) Shandong; (8) Shanghai; (9) Shanxi. The serial numbers of companies industry are: I Animal husbandry; II Chemical raw materials and chemical products manufacturing; III Software and information technology services; IV Pharmaceutical manufacturing; V Metal products industry; VI Computer, communications and other electronic equipment manufacturing; VII Press and publishing industry; VIII Special equipment manufacturing; IX General equipment manufacturing; X Electrical machinery and equipment manufacturing industry; XI Internet and related services; XII Research and experimental development.

\begin{tabular}{|c|c|c|c|c|c|c|c|c|}
\hline Stock abbreviation & Stock code & Location & Industry & $\mathrm{F} 1$ & $\mathrm{~F} 2$ & F3 & $\mathrm{F} 4$ & $\mathrm{~F}$ \\
\hline Wens & 300,498 & (1) & I & 37 & 4 & 1 & 24 & 1 \\
\hline Jinke Culture & 300,459 & (2) & II & 10 & 36 & 35 & 1 & 2 \\
\hline Century Network & 300,494 & (3) & III & 1 & 45 & 34 & 43 & 3 \\
\hline Science Sun Pharmaceutical & 300,485 & (4) & IV & 2 & 7 & 43 & 46 & 4 \\
\hline Lucky Innovatie Materials & 300,446 & (5) & II & 4 & 1 & 24 & 85 & 5 \\
\hline ESTTOOLS & 300,488 & (2) & $\mathrm{V}$ & 3 & 13 & 56 & 53 & 6 \\
\hline TFC Optical & 300,394 & (6) & VI & 6 & 3 & 50 & 65 & 7 \\
\hline ChineseAll & 300,364 & (4) & VII & 9 & 84 & 51 & 2 & 8 \\
\hline Jinlei Wind Power & 300,443 & (7) & VIII & 23 & 5 & 53 & 16 & 9 \\
\hline LiXing CO., LTD. & 300,421 & (6) & IX & 5 & 78 & 27 & 11 & 10 \\
\hline Information Development & 300,469 & (8) & III & 59 & 74 & 29 & 41 & 78 \\
\hline Hanbang Technology & 300,449 & (4) & IX & 36 & 75 & 36 & 73 & 79 \\
\hline Failong Crystal & 300,460 & (1) & VIII & 51 & 72 & 45 & 68 & 80 \\
\hline Tanac Automation & 300,461 & (2) & VIII & 80 & 60 & 78 & 13 & 81 \\
\hline Luyitong & 300,423 & (7) & $\mathrm{x}$ & 40 & 61 & 70 & 76 & 82 \\
\hline $\begin{array}{l}\text { New Universal Science } \\
\text { and Technology }\end{array}$ & 300,472 & (4) & VIII & 60 & 70 & 67 & 60 & 83 \\
\hline Precise & 300,442 & (8) & VIII & 45 & 82 & 54 & 79 & 84 \\
\hline Baofeng Group & 300,431 & (4) & $\mathrm{XI}$ & 32 & 86 & 10 & 14 & 85 \\
\hline Boji Medical \& Biotechnological & 300,404 & (1) & XII & 19 & 85 & 87 & 86 & 86 \\
\hline $\mathrm{OMH}$ & 300,486 & (9) & VIII & 21 & 87 & 76 & 87 & 87 \\
\hline
\end{tabular}

Table 3. The top 10 and the last 10 ranking companies based the overall factor scores. 


\section{Conclusions and Analysis}

The geographical distribution is not even and includes 18 provinces, of which 16 in Beijing, 14 in Guangdong province, 9 in Jiangsu province, 10 in Sichuan province, 9 in Zhejiang province, 5 in Shanghai and the rest 25\% of the companies scatter across 12 provinces.

The industry distribution of 87 public companies listed on the China's GEM in 2015 is also uneven, of which $81.6 \%$ operate in manufacturing, IT and related servicing industries, while others only occupy $19.4 \%$. This implies a need to further develop enterprises in culture \& sports, entertainment, healthcare and social activities.

The result of conducting factor analysis on SPSS has shown that, there are differences in competitiveness between the above-mentioned 87 listed companies, both within the same industry or between different ones. The comprehensive factor scores of the top 10 companies are $2.0133,1.9386,1.1839,1.1439$, $1.0994,0.8474,0.7765,0.4792,0.4353,0.4270$ and the comprehensive factor scores of the last 10 companies are $-0.3964,-0.3969,-0.4192,-0.4198,-0.4369$, $-0.5458,-0.6686,-0.7402,-0.7493,-1.4267$.

The No. 1 ranking company "Wens" is the only one who operates in animal husbandry. According to Table 3, the company has an outstanding operating ability and ranks among the best candidates for profitability. Its net assets value per share is 7.002 yuan and P/E ratio is 13 . The market value of "Wens" is undervalued in China's A share market.

The $8^{\text {th }}$ ranking company "ChineseAll" is the only publisher among the 87 listed companies and is also a digital media company in China A-share market. With the growth of China's Per Capita GDP, consumer demand is upgraded and shifted towards demands for culture, entertainment and education from the basic necessities of life. The size of China's digital publishing industry continues to grow, the rate of digital reading gradually increases and, digital publishing continues to apply in the education industry. "ChineseAll" was established in Tsinghua University in 2000, as one of the pioneers of digital publishing in China. Since its establishment, the company's focus has always been driving business operations with technology development and the tracing, studying and exploration of digital publishing related techniques. Its related technology covers the production, processing, operations, publishing and utilization of digital contents. Meanwhile, "ChineseAll" also involves in the related technology of standard date formats, industry standards and digital right protections. The company's technology advantages are outstanding. "ChineseAll" used its vast technological superiority to drive business operations. Now, the company develops around "literature +", "education +", which is the role model of the cultural industry with new service standards. According to Table 3, the firm ranks second in growth capability but $84^{\text {th }}$ in profitability. Its profitability needs to be improved.

Only one of the top 10 companies engages in special equipment manufactur- 
ing, and among the last 10 listed companies, five engage in special equipment manufacturing.

"Jinlei Wind Power" services for the global high-end and middle-end wind turbine manufacturers and engages in research, production and sales of wind power spindle and open-die forgings. "Jinlei Wind Power" is committed to technological innovation and R\&D. It has 12 core technologies, 7 of which are in domestic advanced levels. It has a complete production process of wind power spindle. It has the advantage of customer resources. In 2016, its domestic market share and global market share was $11.65 \%$ and $14.36 \%$. Its customers included GE, Siemens, Gamesa, United Power, Envision, which were among the top 10 wind turbine manufacturers in 2016 according to the "Renewable Energy World" magazine.

The profitability and growth capacity of "OMH" came last among the 87 companies, due to the fact that its main revenue driver is the intelligent logistics delivery system. Affected by the decrease of fixed asset investment in the auto industry, revenue of "OMH" was significantly reduced.

"Precise" engaged in research, production and sales of liquid food packaging machinery and aseptic packaging materials. Affected by the depression in the liquid food industry during 2016, the demand for raw material of liquid food packages and liquid food packaging machines sharply decreased, which led to a substantial decline in the company's operating profit.

In short, each stock has countless seemingly purchase basis. By careful study and observation, the elements of a company's success will be found. And investors can get great profits from the companies with good products and good business models.

\section{References}

[1] Cetindamar, D. and Kilitcioglu, H. (2013) Measuring the Competitiveness of a Firm for an Award System. Competitiveness Review: An International Business Journal, 23, 7-22. https://doi.org/10.1108/10595421311296597

[2] Kamukama, N. (2013) Intellectual Capital: Company's Invisible Source of Competitive Advantage. Competitiveness Review: An International Business Journal, 23, 260-283. https://doi.org/10.1108/10595421311319834

[3] Liu, Y. and Wei, J. (2013) Business Modeling for Entrepreneurial Firms: Four Cases in China. Chinese Management Studies, 7, 344-359.

https://doi.org/10.1108/CMS-Mar-2012-0052

[4] Zineldin, M. (2005) Quality and Customer Relationship Management (CRM) as Competitive Strategy in the Swedish Banking Industry. The TQM Magazine, 17, 329-344. https://doi.org/10.1108/09544780310487749

[5] Elahi, E. (2013) Risk Management: The Next Source of Competitive Advantage. Foresight, 15, 117-131. https://doi.org/10.1108/14636681311321121

[6] Zhang, H.-T., Zhen, Z. and Ma, C. (2014) Research on the Evaluation Index System of Insurance Company-Competitiveness Based on Pairwise Comparison Matrix Method. Journal of University of Science and Technology Beijing (Social Sciences Edition), No. 1, 102-113. 
[7] Wang, J., Wang, L.-F. and Zhou, J. (2013) Empirical Study on Evaluation of Competitiveness of Listed Department Stores from Financial Perspective. Journal of Beijing Technology and Business University (Social Sciences), No. 3, 40-46.

[8] Chen, Q.-J. and Wang, X.-F. (2014) The Competitiveness Evaluation and Analysis of Influencing Factors of Tibet Listed Companies. Journal of Tibet, 29, 55-61.

[9] Huang, S.-Y. and Xu, Q. (2009) Competitiveness Evaluation about Listed Companies in Liaoning Province Based on the Financial Indicators. Journal of Liaoning Normal University (Social Sciences Edition), No. 5, 45-47.

[10] Liu, H.-J. and Wang, S.-W. (2015) Analysis of the Competiveness of Growth Enterprise Market Listed Companies in China-Empirical Study Based on Grey System Theory through MATLAB. Journal of Dalian University of Technology (Social Sciences Edition), 36, 7-11. 